\title{
Oral L-Alloisoleucine Loading Studies in Healthy Subjects and in Patients with Maple Syrup Urine Disease
}

\author{
PETER SCHADEWALDT, CHRISTIAN DALLE-FESTE, ULRICH LANGENBECK, AND \\ UDO WENDEL \\ Institut für Physiologische Chemie II [P.S., C.D-F.], Diabetes Forschungs-institut [P.S.], and Kinderklinik \\ [U.W.], Universität Düsseldorf, D-4000 Düsseldorf, Germany and Institut für Humangenetik [U.L.], \\ Universität Frankfurt, D-6000 Frankfurt/Main, Germany
}

\begin{abstract}
Total body and renal elimination of L-alloisoleucine was assessed after oral loads $(0.57 \mathrm{mmol} / \mathrm{kg}$ body wt) in four healthy subjects and in five patients with maple syrup urine disease (MSUD) of different degrees of severity. As judged from the fictive initial concentration, $\mathrm{L}$-alloisoleucine is distributed evenly in the total body water space. In the controls, estimated half-time of total elimination was $9.2 \pm 2.2 \mathrm{~h}(n=4)$. In the MSUD patients, it ranged from $26 \mathrm{~h}$ (mild variant) to about $8 \mathrm{~d}$ (classical type). Because of its low renal clearance rate, $\mathrm{L}$-alloisoleucine was cleared through ketomethylvalerate to $>99 \%$ in normals and to at least $73 \%$ in the MSUD patients. Assuming small variation in the losses of ketomethylvalerate through $\mathrm{L}$-isoleucine formation and through renal excretion, this test allows ranking of MSUD patients with regard to their residual in vivo branched-chain oxo-acid dehydrogenase activity. (Pediatr Res 30: 430-434, 1991)
\end{abstract}

\section{Abbreviations}

allo, $\mathrm{L}$-alloisoleucine

BCAA, branched-chain amino acids

BCOA, branched-chain 2-0xo acid

ile, $\mathrm{L}$-isoleucine

KMV, 3-methyl-2-oxopentanoate (ketomethylvalerate)

MSUD, maple syrup urine disease

$\mathbf{k}_{\mathrm{e}}$, elimination constant

$\mathbf{Y}_{0}$, fictive initial concentration

Allo is a normal constituent in human plasma, yet reliable detection by common chromatographic methods is difficult because of its very low concentration $(<5 \mu \mathrm{mol} / \mathrm{L})(1,2)$. High concentrations were first found by Norton et al. (3) in patients with MSUD, in which BCAA catabolism is impaired because of an inherited deficiency in BCOA dehydrogenase complex (E.C. 1.2.4.4) activity (see Refs. 4-7 for reviews). Increased plasma levels of allo appear to be pathognomonic for MSUD (7).

In the body, allo is formed by retransamination of (R)-KMV The latter is the product of oxo-enol tautomerization of (S)$\mathrm{KMV}$, which in turn originates from transamination of ile $(2,3$, $6,8-10)$. Allo is not bioavailable for protein synthesis (11), and urinary excretion of this amino acid and its derived 2-oxo acid is very low $(2,6,11-14)$. Clearance of allo loads from the body,

Received January 3, 1991; accepted May 20, 1991.

Correspondence: Dr. Peter Schadewaldt, Diabetes-Forschungsinstitut, Universität Düsseldorf, Auf'm Hennekamp 65, D-4000 Düsseldorf, Germany.

Supported in part by Grant We 614/6-3 from the Deutsche Forschungsgemeinschaft. therefore, seems to be confined primarily to metabolic degradation via the so called "R-pathway" of ile metabolism (15). Accordingly, "natural" allo blood levels related to simultaneous ile levels were found to correlate with the residual in vitro activity of BCOA dehydrogenase (10).

Besides these more general findings, little is known of the quantitative aspects of in vivo allo catabolism in man (4) and there is, to our knowledge, only one former report on allo loading experiments (6).

Here we report on clearance rates after oral loads of allo in four healthy subjects and five patients with MSUD of different degrees of severity. Two questions were asked in the present study: 1) To what extent does the allo catabolism differ between normals and MSUD patients in vivo and 2) does the allo elimination constant provide a better in vivo indicator of the severity of the disease than the "natural" plasma allo/ile ratio reported previously $(10)$ ?

\section{MATERIALS AND METHODS}

Chemicals. Unless otherwise noted, all chemicals were purchased in the highest available purity from Merck (Darmstadt, Germany) or Sigma (Deisenhofen, Germany). Allo was obtained from Bachem (Heidelberg, Germany). As checked by amino acid and 2-oxo acid analysis (see below), it contained less than $1.5 \%$ ile and no KMV.

Alloisoleucine loads. In general, probands and patients received $0.57 \mathrm{mmol}$ allo $/ \mathrm{kg}$ body weight p.o. around $1300 \mathrm{~h}$. Venous blood was collected in a heparizined syringe just before the load (control value) and thereafter in varying time intervals as indicated in the figures. In four of the loading experiments, spontaneous urine was collected in parallel with the blood samples to allow an estimation of renal clearance rates. The study had been approved by the Ethical Committee of the Düsseldorf Medical Faculty.

Assays. BCAA concentrations in body fluids were measured on an automatic amino acid analyzer (LC 6000 or LC 6001 ; Biotronic, Munich, Germany). In general, the short program for BCAA of Benson et al. (16) as modified by Schadewaldt et al. (2) was used. For the estimation of the BCOA, the respective quinoxalinol derivatives were analyzed by reversed phase HPLC using 2-oxohexanoate as an internal standard as described previously (17). Creatinine was measured enzymatically (18) on a Hitachi 704 analyzer (Boehringer, Mannheim, Germany). BCOA dehydrogenase activity in intact skin fibroblasts was assayed in microtest plates as described previously (19). $\mathrm{L}-\left[1-{ }^{14} \mathrm{C}\right]$ leucine (1 $\mathrm{mmol} / \mathrm{L}$ ) was used as a substrate.

Patients. The MSUD patients, at times of good metabolic control, were deliberately chosen for this study on the basis of 
their different phenotypes: classic form, TA (female, born in 1974); severe variant, MO (female, born in 1977); variants, GU (female, born in 1974) and AC (female, born in 1982); and mild variant, NA (male, born in 1978). Classification into classic and variant forms was made according to the clinical course, the dietetic leucine tolerance, and biochemical findings (17). All these patients have been described previously $(10,20,21)$.

Four healthy adults with normal body weight served as controls. Matched controls (i.e. healthy children) were not available for the experiments.

Calculations. The time course of the decrease of the allo plasma levels, starting with the data $5-8 \mathrm{~h}$ postload, was subjected to pharmacokinetic analysis using a one-compartment model with single exponential decay. The results were estimates of $\mathrm{k}_{\mathrm{c}}$ and $Y_{0}$. In MSUD patients, a first calculation was made for estimating $\mathrm{k}_{\mathrm{c}}$. The preload allo levels in the patients were then used for calculation, with the $\mathrm{k}_{\mathrm{e}}$ estimate, of corrected postload levels. They yielded, in a second calculation, a rough estimate of $Y_{0}$ also for the patients. We used the PC-based ENZFITTER software package (22), which applies Marquardt's enhanced algorithm to the untransformed data. The software, with automatic guess of initial estimates and with simple and robust weighting, arrived at stable estimates after three to four iterations. Further pharmacokinetic calculations followed standard procedures (23). Body surface was calculated with the equation of Dubois and Dubois (24).

Renal clearance rates $\left(C_{R}\right)$ were approximatively estimated using a modified clearance formula:

$$
\mathrm{C}_{\mathrm{R}}=\left([\mathrm{P}]_{\mathrm{u}} \cdot \mathrm{V}_{\mathrm{u}}\right) /\left\{\left[\left([\mathrm{P}]_{\mathrm{t}_{1}}+[\mathrm{P}]_{\mathrm{t}_{2}}\right) \times 0.5\right] \cdot\left(\mathrm{t}_{2}-\mathrm{t}_{1}\right)\right\}
$$

where $[\mathrm{P}]_{\mathrm{u}}$ was the metabolite concentration in and $\mathrm{V}_{\mathrm{u}}$ the volume of the urine collected between two successive time points $t_{1}$ and $t_{2}$, and $[P]_{t_{1}}$ and $[P]_{t_{2}}$ were the concentrations in plasma samples withdrawn at $t_{1}$ and $t_{2}$ after start of the allo load. The time intervals chosen were the same as in the main study. 1).

Results are given as mean $\pm \mathrm{SD}$, unless stated otherwise (Table

\section{RESULTS}

Distribution of allo. The apparent volume of distribution was compared with total body water data for adults (related to weight, sex, and age groups) in the study by Edelman and Leibman (25) and with the body weight-related function of Gladtke (26) for children and juveniles. The experimental estimates of volume of distribution differed from nominal total body water by $6 \pm 17 \%$ $(n=8)$.

Total body elimination of allo. Over the time of observation (up to about $60 \mathrm{~h}$ in controls and up to about $15 \mathrm{~d}$ in MSUD), there were no systematic deviations from a single exponential decay: The residuals were randomly and evenly distributed over the time period (Figs. 1 and 2 ). The residual $\chi^{2}$, as provided by the software, allows comparisons of the goodness of fit between the different oral loading experiments. No consistent changes in the plasma levels of the other BCAA were observed in our allo loading experiments.

The estimates of $k_{e}$ are given in Table 1. In normal controls, mean $\mathrm{k}_{\mathrm{e}}$ was $1.89 \pm 0.43 \mathrm{~d}^{-1}$, which corresponds to a normal plasma half-time of $9.2 \pm 2.2 \mathrm{~h}$. In MSUD patients, the decline of allo plasma levels was considerably delayed and was related to the severity of the disease (Table 1 and Fig. 2). Estimated plasma half-times ranged from $26 \mathrm{~h}$ in variant $\mathrm{AC}$ to about $8 \mathrm{~d}$ in the classic type patient TA.

The total body clearance (t.b.cl.) in the control subjects was calculated from $\mathrm{k}_{\mathrm{e}}$ and actual volume of distribution. Because in MSUD patients the $Y_{0}$ is subject to larger experimental errors, t.b.cl. has been calculated as t.b.cl. $=\mathrm{k}_{\mathrm{e}} \cdot[(0.535 \cdot \mathrm{kg}+0.223$. $\left.\left.\mathrm{kg}^{0.762}\right) /\left(71.84 \cdot \mathrm{kg}^{0.425} \cdot \mathrm{cm}^{0.725}\right)\right] \cdot 1.73 \cdot 10.000$. This procedure assumes even distribution of allo in the total body water (see above) and combines the equations for surface area (24) and body water in children (26). The estimates of the t.b.cl. in controls and patients are given also in Table 1.

Renal clearance of $B C A A$ and $B C O A$. The actual clearance data, as obtained in the loading experiments in two normal controls, are given in Table 2. Standardized to $1.73 \mathrm{~m}^{2}$, the renal allo clearance was 19 and $8 \mathrm{~mL} / \mathrm{h}$, respectively. These values correspond to renal elimination constants of 0.012 and 0.004 $\mathrm{d}^{-1}$, respectively, which is 0.2 to $0.7 \%$ of the total $\mathrm{k}_{\mathrm{e}}$ of allo. The renal clearance of allo in two MSUD patients under conditions of good metabolic control was found in the same order of magnitude (Table 1).

Fate of allo carbon. Allo-induced changes in the plasma content of KMV were measured in two control and in two MSUD subjects (data not shown). A reliable method for separate quantification of the (S)- (from ile) and (R)-enantiomer (from allo) is not yet available (10). Total KMV levels increased within a few hours, plateaued for hours or even days, and then gradually declined. As related to controls, height and duration of the plateaus as well as the time-dependent decline of KMV in MSUD corresponded rather well with the apparent severity of the disease in the affected patients.

Efflux of allo through $K M V$. The total body clearance of allo

Table 1. Allo clearance in healthy subjects and MSUD patients after an oral allo load with $0.57 \mathrm{mmol} / \mathrm{kg}$ body wt*

\begin{tabular}{|c|c|c|c|c|c|c|}
\hline \multirow[b]{2}{*}{ Probands } & \multirow[b]{2}{*}{$\mathrm{k}_{\mathrm{e}}\left(\mathrm{d}^{-1}\right) \pm \mathrm{SEM}$} & \multicolumn{2}{|c|}{ Clearance $\left(\mathrm{L} / \mathrm{h} \cdot 1.73 \mathrm{~m}^{2}\right)$} & \multirow[b]{2}{*}{$t_{1 / 2}(d)$} & \multirow{2}{*}{$\begin{array}{c}\text { Plasma concentration } \\
\text { allo/ile } \neq\end{array}$} & \multirow{2}{*}{$\begin{array}{c}\text { \% Residual in vitro ac- } \\
\text { tivity of BCOA dehy- } \\
\text { drogenase }\end{array}$} \\
\hline & & Total body $\uparrow$ & Renal & & & \\
\hline \multicolumn{7}{|l|}{ Control } \\
\hline FDई & $1.609 \pm 0.052$ & 3.006 & ND\| & 0.43 & 0 & 100 \\
\hline $\mathrm{FD}$ & $1.919 \pm 0.046$ & 2.124 & 0.008 & 0.36 & 0 & 100 \\
\hline WK & $2.412 \pm 0.041$ & 2.263 & ND & 0.29 & 0 & 100 \\
\hline WV & $1.364 \pm 0.041$ & 2.126 & ND & 0.51 & 0 & 100 \\
\hline SP & $1.850 \pm 0.130$ & 2.878 & 0.019 & 0.37 & 0 & 100 \\
\hline \multicolumn{7}{|l|}{ MSUD } \\
\hline $\mathrm{AC}$ & $0.637 \pm 0.001$ & 0.746 & ND & 1.09 & ND & 4 \\
\hline NA & $0.550 \pm 0.013$ & 0.672 & ND & 1.26 & 0.09 & 19 \\
\hline GU & $0.195 \pm 0.006$ & 0.334 & 0.012 & 3.55 & 0.56 & 8 \\
\hline MO & $0.104 \pm 0.006$ & 0.153 & ND & 6.66 & 0.38 & 3 \\
\hline $\mathrm{TA}$ & $0.089 \pm 0.008$ & 0.112 & 0.030 & 7.79 & 0.55 & $<1$ \\
\hline
\end{tabular}

* See Figures 1 and 2 and Materials and Methods.

$\dagger$ See Results.

$\ddagger$ Data are in part from Reference 10 .

$\S$ In this experiment the load was $0.38 \mathrm{mmol} / \mathrm{kg}$ body wt.

II ND, not determined. 

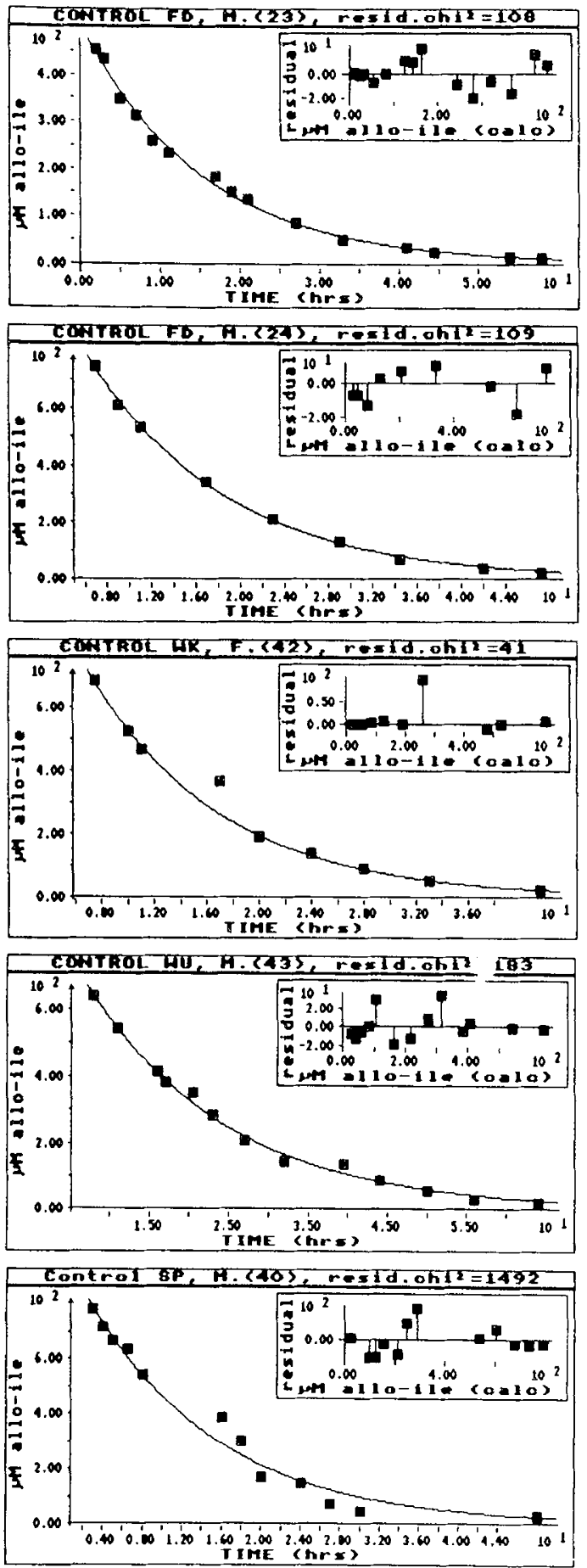

Fig. 1. Time course of allo (here abbreviated as allo-ile) concentrations in plasma of four healthy subjects after an oral allo load $(0.57$ $\mathrm{mmol} / \mathrm{kg}$ body wt). Proband FD also received a load of $0.38 \mathrm{mmol} / \mathrm{kg}$ body wt. Basal levels of allo are about $5 \mu \mathrm{M}$. Sex and age (y) are given in the headings. The residual $\chi^{2}$ is a comparative measure of the goodness of fit, and the inserts demonstrate the residuals toward the calculated single exponential decay function (Marquardt's algorithm on nontransformed data).

was $2.35 \pm 0.36 \mathrm{SD} \mathrm{L} \cdot \mathrm{h}^{-1} \cdot 1.73 \mathrm{~m}^{2}$ in the controls. In MSUD patients AC (variant) and TA (classic), estimates of $0.75 \mathrm{~L} \cdot \mathrm{h}^{-1}$. $1.73 \mathrm{~m}^{2}\left(30 \%\right.$ of control) and $0.11 \mathrm{~L} \cdot \mathrm{h}^{-1} \cdot 1.73 \mathrm{~m}^{2}(4 \%$ of control), respectively, were obtained. Correcting for the renal allo clearance (Table 1), these findings indicate that in MSUD patients from $73 \%$ to more than $96 \%$ of an allo load leaves the body through formation of KMV and its subsequent renal and metabolic handling. In controls, this fraction exceeds $99 \%$.
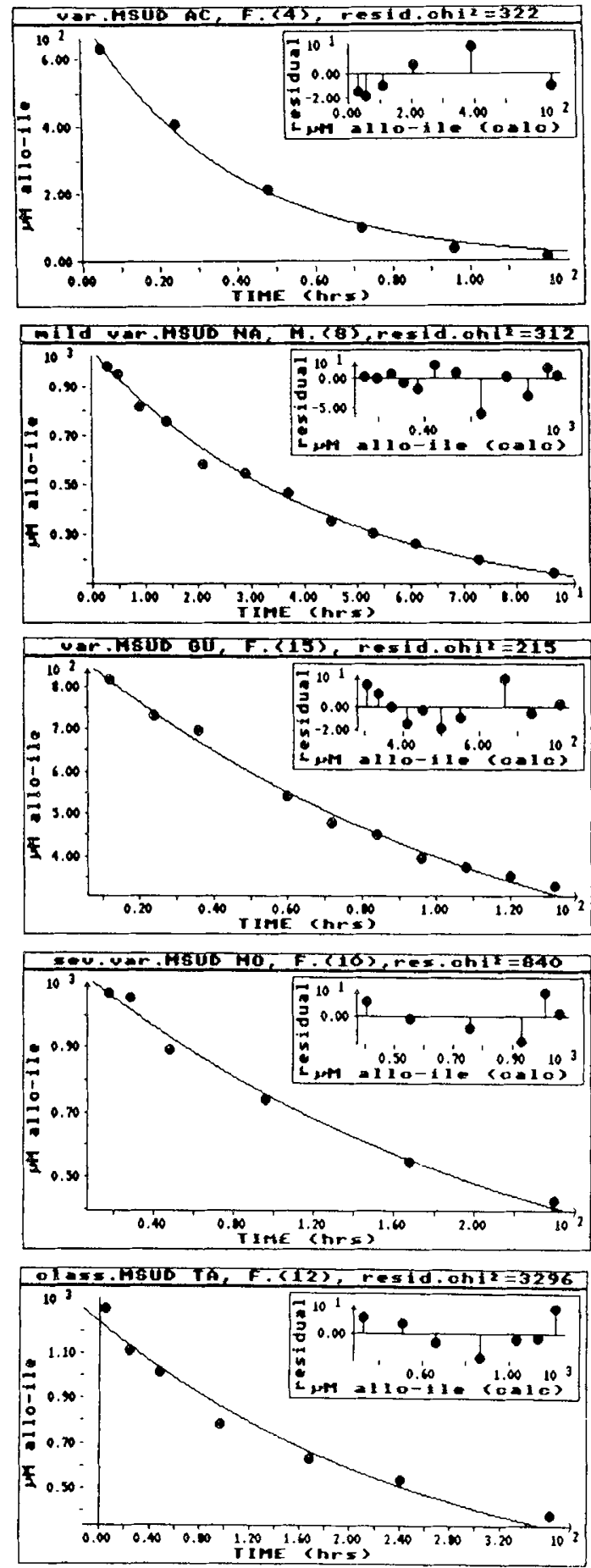

Fig. 2. Time course of allo (allo-ile) concentrations in plasma of five MSUD patients with different degrees of severity after an oral allo load $(0.57 \mathrm{mmol} / \mathrm{kg}$ body $\mathrm{wt})$. Venous blood was withdrawn just before load (basal value). See legend to Figure 1 for further details.

\section{DISCUSSION}

In the study presented here, we have provided estimates for the in vivo catabolism of allo in normal subjects and in patients with MSUD. These data confirm and extend a previous study of Snyderman et al. (6), who found the allo plasma half-lives of 5.5 and $7.5 \mathrm{~d}$, respectively, in two patients with classic MSUD.

Our calculations are based primarily on the time course of allo plasma concentrations after an oral allo load. At the latest, 5-8 h after oral load, the plasma levels of allo faithfully followed a single exponential elimination function. The volume of distribution was estimated using this function and was found to be 
Table 2. Estimated renal clearance of branched-chain compounds and of creatinine in two healthy subjects during allo load*

\begin{tabular}{|c|c|c|c|c|}
\hline \multirow[b]{2}{*}{ Compound } & \multicolumn{2}{|c|}{ Subject SP } & \multicolumn{2}{|c|}{ Subject FD } \\
\hline & $\begin{array}{c}\text { Mean rate } \\
\pm \mathrm{SD} \\
(\mathrm{mL} / \mathrm{min})\end{array}$ & $\begin{array}{c}\text { Total } \\
(\mu \mathrm{mol} / 24 \mathrm{~h})\end{array}$ & $\begin{array}{c}\text { Mean rate } \\
\pm \mathrm{SD} \\
(\mathrm{mL} / \mathrm{min})\end{array}$ & $\begin{array}{c}\text { Total } \\
(\mu \mathrm{mol} / 24 \mathrm{~h})\end{array}$ \\
\hline Allo & $0.32 \pm 0.11$ & 183 & $0.13 \pm 0.03$ & 80 \\
\hline KMV & $0.23 \pm 0.11$ & 48 & $0.58 \pm 0.27$ & 62 \\
\hline L-Valine & $0.34 \pm 0.11$ & 113 & $0.23 \pm 0.06$ & 107 \\
\hline Ile & $0.83 \pm 0.23$ & 91 & $0.29 \pm 0.04$ & 67 \\
\hline L-Leucine & $0.42 \pm 0.10$ & 77 & $0.39 \pm 0.11$ & 67 \\
\hline Creatinine & $157 \pm 40$ & & $202 \pm 50$ & \\
\hline
\end{tabular}

* Data refer to the experiments shown in Figure 1 and Tabie 1. Rates are standardized to $1.73 \mathrm{~m}^{2}$ body surface. They were estimated on the basis of the plasma concentrations and the renal excretions in the sampling periods during the 1 st and 24th $\mathrm{h}$ after allo ingestion. Timedependent changes of clearance rates were not observed. Total clearance represents the sum of metabolites that were excreted within $24 \mathrm{~h}$ after the load. Urinary concentrations of BCOA other than KMV were too low to be evaluated.

close to the nominal total body water space in all individuals. This is not unexpected, because the BCAA do not bind to plasma proteins and are normally not concentrated in or excluded from cells or tissues $(4,7,27)$. The elimination of allo from plasma therefore reflects elimination from total body in the sense of a one-compartment model. These considerations do not apply to the BCOA, for which considerable plasma protein binding has been demonstrated $(7,28)$ and for which plasma and muscle levels do differ $(29,30)$. For these reasons and because the renal BCOA clearance is concentration dependent (14), a further kinetic analysis (modeling) was not attempted with the present data.

Renal excretion of allo plays almost no role in its elimination from the body. We found this contribution to be less than $1 \%$ of total body clearance in normal controls, $4 \%$ in MSUD variant case GU, and still only $27 \%$ in the classic MSUD case TA. It thus appears that MSUD patients lose most of an oral load of allo through formation of KMV and subsequent reactions, e.g. renal loss of KMV. Our data give no hint to the real extent of formation of ile from allo via (R)- and (S)-KMV. We can only surmise that this route, under the conditions of our loading test $(0.570 \mathrm{mmol}$ per $\mathrm{kg}$ body wt at times with more or less normal BCAA plasma levels), bears no major significance, because consistent increases of plasma ile levels could not be seen. In recent papers, we have discussed these points with reference to a socalled "metabolic trap" model of allo metabolism $(2,10)$.

The rather close correlation between $k_{e}$ of allo and clinical type in MSUD patients strongly suggests that the residual activity of BCOA dehydrogenase is the rate-limiting step of all the Rpathway, at least in MSUD patients. Therefore, the $k_{e}$ of allo as determined from sequential plasma levels after an oral allo load appears to be a better indicator of clinical type than the residual in vitro $\mathrm{BCOA}$ dehydrogenase activity or the previously reported plasma allo/ile ratio (10) and (Table 1): The parameter $k_{e}$ is much better defined, and the spread of parameter values across patients of different clinical types is more pronounced. Closer scrutiny of discrepancies between in vivo and in vitro data, which are also seen with in vivo ${ }^{13} \mathrm{C}$-leucine studies (31), may contribute in the future to a better understanding of the pathophysiology of MSUD.

We are presently trying to find out whether the $\mathrm{k}_{\mathrm{e}}$ estimates in different patients may vary significantly over prolonged periods of time. Such data would also contribute to the question of possible regulatory changes of the residual in vivo BCOA dehydrogenase activity in different types of MSUD, e.g. in the stillenigmatic intermittent cases (7).
The in vivo estimation of residual BCOA dehydrogenase activity by loading with the nonprotein amino acid allo offers considerable advantages in the evaluation of MSUD patients, because problems of pool size and protein synthesis are efficiently minimized, without recourse to stable isotope studies. There is ample evidence in the literature (7) that leucine and/or 2-oxo isocaproic acid are the prime toxic metabolites in MSUD. This will exclude experimental leucine tolerance studies for medical as well as for ethical reasons. Our present study has demonstrated that a safe and efficient alternative method is now available.

Acknowledgments. The authors thank H.-W. Hammen for help with the amino acid analysis. Serum samples from patient AC were kindly provided by Dr. Plöchl, Salzburg, Austria.

\section{REFERENCES}

1. Mitch WE, Walser M, Sapir DG 1981 Nitrogen sparing induced by leucine compared with that by its keto analogue, $\alpha$-ketoisocaproate, in fasting obese man. Clin Invest 67:553-562

2. Schadewaldt P, Hammen H-W, Dalle-Feste C, Wendel U 1990 On the mechanism of $\mathrm{L}$-alloisoleucine formation: studies on a healthy subject and with fibroblasts from normals and patients with maple syrup urine disease. $J$ Inherited Metab Dis 13:137-150

3. Norton PM, Roitman E, Snyderman SE, Holt LE 1962 A new finding in maple-syrup-urine disease. Lancet 1:454-455

4. Tanaka K. Rosenberg LE 1983 Disorders of branched-chain amino acid and organic acid metabolism. In: Stanbury JB, Wyngaarden JB, Fredrickson DS, Goldstein JL, Brown MK (eds) The Metabolic Basis of Inherited Disease 5th Ed. McGraw-Hill, New York, pp 440-457

5. Danner DJ, Elsas II LJ 1989 Disorders of branched chain amino acid and keto acid metabolism. In: Scriver CR, Beaudet AL, Sly WS, Valle D (eds) The Metabolic Basis of Inherited Disease, 6th Ed. McGraw-Hill, New York, pp $671-692$

6. Snyderman SE, Norton PM, Roitman E, Holt LE 1964 Maple syrup urine disease, with particular reference to dietotherapy. Pediatrics 34:454-472

7. Langenbeck U 1984 Pathobiochemical and pathophysiologic analysis of the MSUD phenotype. In: Adibi SA, Fekl W Langenbeck U. Schauder P (eds) Branched Chain Amino and Keto Acids in Health and Disease. Karger. Basel/New York, pp 315-344

8. Meister A 1951 Studies on $d$ - and $l-\alpha$-keto- $\beta$-methyl-valeric acid. J Biol Chem $190: 269-276$

9. Matthews DE, Ben-Galim E. Haymond MW, Bier DM 1980 Alloisoleucine formation in maple syrup urine disease: isotopic evidence for the mechanism. Pediatr Res 14:854-857

10. Wendel U, Langenbeck U, Seakins JWT 1989 Interrelation between the metabolism of L-isoleucine and L-allo-isoleucine in patients with maple syrup urine disease. Pediatr Res 25:11-14

11. Batshaw ML, Brusilow S, Walser M 1976 Long-term management of a case of carbamyl phosphate deficiency using ketoanalogues and hydroxyanalogues of essential amino acids. Pediatrics 58:227-235

12. Lancaster G, Mamer OA, Scriver CR 1974 Branched-chain alpha-keto acids isolated as oxime derivatives: relationship to the corresponding hydroxy acids and amino acids in maple syrup urine disease. Metabolism 23:257 265

13. Jacobs C, Solem E, Ek J, Halvorsen K. Jellum E 1977 Investigation of the metabolic pattern in maple syrup urine disease by means of glass capillary gas chromatography and mass spectrometry. J Chromatogr 143:31-38

14. Langenbeck $U$, Wendel $U$, Luthe $H 1979$ Renal clearance of branched-chain 2-oxo acids in maple-syrup-urine disease. J Clin Chem Clin Biochem 17:176177

15. Mamer OA, Tjoa SS, Scriver CR, Klassen GA 1976 Demonstration of a new mammalian isoleucine catabolic pathway yielding an $\mathrm{R}$ series of metabolites. Biochem J 160:417-426

16. Benson JV, Cormick J, Patterson JA 1967 Accelerated chromatography of amino acids associated with phenylketonuria, leucinosis (maple syrup urine disease), and other inborn errors of metabolism. Anal Biochem 18:481-492

17. Schadewaldt P, Beck K, Wendel U 1989 Analysis of maple syrup urine disease in cell culture: use of substrates. Clin Chim Acta 184:47-56

18. Wahlefeld AW, Siedel J 1985 Creatine and creatinine. In: Bergmeyer HU (ed) Methods of Enzymatic Analysis, Vol VII. Verlag Chemie, Weinheim, Germany, pp 488-506

19. Wendel U, Gamm G. Claussen U 1981 Maple syrup urine disease: $\alpha$-ketoisocaproate decarboxylation activity in different types of cultured amniotic fluid cells. Prenat Diagn 1:235-240

20. Schadewaldt $P$, Wendel $W 1989$ Functional differences in the catabolism of branched-chain L-amino acids in cultured normal and maple syrup urine disease fibroblasts. Biochem Med Metab Biol 41:105-116

21. Langenbeck U, Wendel U, Mench-Hoinowski A, Kuschel D, Becker K, Przyrembel $\mathrm{H}$, Bremer HJ 1978 Correlations between branched-chain amino acids and branched-chain $\alpha$-keto acids in blood in maple syrup urine disease. Clin Chim Acta 88:283-291

22. Leatherbarrow RJ 1987 ENZFITTER. A non-linear regression data analysis 
program for the IBM PC (and true compatibles). Elsevier-BIOSOFT, Cambridge, UK

23. Gibaldi M, Perrier D 1982 Pharmacokinetics. Marcel Dekker, New York

24. Dubois D, Dubois EF 1915 The measurement of the surface area of man. Arch Intern Med 15:868-881

25. Edelman IS, Leibman J 1959 Anatomy of body water and electrolytes. Am J Med 27:256-277

26. Gladtke E 1966 Der Thiosulfatraum des Kindes. Arch Kinderheilkd 54, Beiheft 27. Bergström J, Fürst $P$, Noree LO, Vinnars E 1974 Intracellular free amino acid concentrations in human muscle tissue. J Appl Physiol 36:693-697

28. Nissen SL, Miles JM, Gerick JE, Haymond MW 1982 Regulation of $\alpha$ - ketoisocaproate binding to albumin in vivo by free fatty acids. Am J Physiol 242:E67-E71

29. Hutson SM, Zapalowski C, Cree TC, Harper AE 1980 Regulation of leucine and $\alpha$-ketoisocaproic acid metabolism in skeletal muscle. J Biol Chem 255:2418-2426

30. Langenbeck U, Luthe $\mathrm{H}$, Schaper $\mathrm{G} 1985$ Ketoacids in tissues and biological fluids: O-t-butyldimethylsilyl quinoxalinols as derivatives for sensitive gas chromatographic/mass spectrometric determination. Biomed Mass Spectrom 12:507-509

31. Elsas II LJ, Klein PD, Ellerine N, Hachey DL, Sekely S 1989 Screening for maple syrup urine disease by ${ }^{13} \mathrm{C}$-leucine oxidation in vivo. Soc Study Inborn Errors Metab Proc Symp 68 (abstr)

\section{Announcement}

\section{American Board of Nutrition}

\section{Examination}

The next certifying examination of the American Board of Nutrition will be administered on May 1 and 2 , 1992 in conjunction with the Annual Meeting of The American Society for Clinical Nutrition in Baltimore, MD.

Individuals with a doctoral degree (M.D., Ph.D., or equivalent) and appropriate nutrition background are eligible to take the examination. M.D. candidates must be certified by a primary board recognized by the American Board of Medical Specialties and have completed at least 2 years of appropriate nutrition training at the time of the examination.

Deadline for receipt of academic records and sponsoring letters is January 2, 1992.

For more detailed information, write to: American Board of Nutrition, 9650 Rockville Pike, Bethesda, MD 20814. Telephone (301) 530-7110. 